\title{
Designing for resilience: permaculture as a transdisciplinary methodology in applied resilience research
}

\author{
Thomas W. Henfrey, ${ }^{1,2}$
}

\begin{abstract}
In this paper I examine the relationship between resilience research and permaculture, a system for the design and creation of human habitats, organizations, and projects rooted in ethics of sustainability, well-being, and equity. I argue that applying permaculture as a tool in research design can enable research to contribute more directly, immediately, and effectively to building community resilience. I explore this argument with reference to three case studies of research projects that involve permaculture as both research topic and methodology, at multiple geographical scales. Each of these cases provides evidence that research activities contribute to community resilience, and that this can be attributed to the application of permaculture principles and methods in research design. In particular, permaculture embeds iterative processes of action learning able to enhance adaptive capacity within communities in which it is applied. This includes transdisciplinary communities that mobilize around specific research interests and communities of place and/or practice that participate in transdisciplinary research. I suggest that this may be an instance of a general situation whereby research both incorporates and enhances existing learning processes that contribute to adaptive capacity and community resilience. I tentatively propose for such collaborations the label "Mode 3" resilience research, and suggest further research be done to identify and examine further cases in both permaculture and other fields of resilience research.
\end{abstract}

Key Words: community resilience; participatory action research; permaculture; transdisciplinary research; transformation

\section{INTRODUCTION: COMMUNITY RESILIENCE AND MODE 2 SCIENCE}

In this paper I examine the relationship between permaculture and resilience research. Specifically, I explore how social permaculture can form the basis of transdisciplinary methodologies in which research directly and deliberately contributes to efforts to build community resilience. This exploration draws on three case studies of research collaborations in which I was personally involved. I locate the argument in a wider analysis of the nature of participation in resilience research and the methodological, epistemological, and political implications of collaboration with community-based resilience practitioners. In conclusion I suggest that increased levels of critical introspection concerning normative aspects is necessary for full realization of the applied potential of resilience research, and point toward a possible new orientation that foregrounds these reflexive dimensions.

Conceptually, I employ definitions of resilience derived from both scientific literature and the ways scientific concepts are interpreted, mobilized, and operationalized in self-organized, place-based initiatives that aim to generate community resilience (Henfrey and Giangrande 2017). A classic, and relevant, definition of resilience from the social-ecological systems literature is, "the capacity of a system to absorb disturbance and reorganize while undergoing change so as to still retain essentially the same function, structure, identity, and feedbacks" (Walker et al. 2004). Consideration of community resilience demands attention to the ability of human actors to exercise agency, including in developing individual and collective capacity to negotiate and/or instigate change. This leads to definitions such as, "Community resilience is the existence, development, and engagement of community resources by community members to thrive in an environment characterized by change, uncertainty, unpredictability, and surprise" (Magis 2010:402).

Combining insights from resilience theory and community development literatures on the social and psychological aspects of individual and collective responses to change, Berkes and Ross (2013) identify a number of key features of community resilience. These relate to infrastructure, livelihoods, and economies in addition to ecological and social factors, and describe how communities exercise and develop their capacities for selforganization and agency. This takes place through connection to place, beliefs and values, social networks, knowledge and learning, economic diversity, economic innovation, collaborative governance, infrastructure, leadership, and maintaining a positive outlook in the face of change. Berkes and Ross also stress the importance of the concept of panarchy, i.e., the community's complex interrelationships with systems at regional, national, and global levels (Berkes and Ross 2013). In current circumstances these wider systems are structurally dependent upon patterns of usage and allocation of resources that are inherently unsustainable and inequitable (Barry 2012). In the hands of community-based actors committed to sustainability and social justice, including those involved in the case studies on which this paper is based, resilience therefore becomes a necessarily transformative concept that actively seeks radical reconfiguration of dominant systems of production and consumption and the values and worldviews that underlie them (Henfrey et al. 2017). This contrasts with the convention in the social-ecological resilience literature to distinguish resilience from transformability: "The capacity to create a fundamentally new system when ecological, economic, or social (including political) conditions make the existing system untenable" (Walker et al. 2004). Community resilience does not only refer to the capacity of a

${ }^{1}$ Centre for Ecology, Evolution and Environmental Change (cE3c), CCIAM - Climate Change research group, Faculdade de Ciências da Universidade de Lisboa (FCUL), Portugal, ${ }^{2}$ Schumacher Institute for Sustainable Systems, Bristol, UK. 
group of people united by common interest to exercise agency in responding to change locally. It also takes into account their ability to instigate and contribute to transformation in the wider systems in which they are nested, because the latter are fundamentally incompatible with resilience at the scale of the local community.

In relation to methodological assessment, an existing framework that can be adapted to our present purposes is Sterling's typology of approaches to sustainability education. This identifies three different levels: education on sustainability, education for sustainability, and education as sustainability in practice (Sterling 2001). The latter, revisited in the conclusion to this paper, seeks to create institutional settings, pedagogical methods, and learning cultures that themselves model sustainability in practice. Very different in nature from approaches embedded in unsustainable wider systems, and lacking established precedents, approaches of this kind are of necessity experimental (Orr 1994). They form microcosms of wider processes of societal learning toward a more sustainable society. Permaculture is a paradigmatic example of this: a popular education movement that seeks to cocreate a society rooted in ethics of sustainability, social justice, and equity through nested and intersecting processes of action learning (Henfrey 2017).

Parallel to Sterling's typology is the distinction between Mode 1 and Mode 2 science (Regeer and Bunders 2009). Mode 1 science considers itself to be detached from its research subjects, from civil society action, and indeed from all forms of social agency. Its role in addressing societal problems is seen as limited to documentation of social and other phenomena, thus providing information that can inform policy and other processes with legitimate roles in structuring society. In Mode 2, scientists take part in transdisciplinary partnerships, collaborating with civil society and other forms of nonscientific partner in order to identify and help address societal issues. Mode 2 science is thus explicitly positional and change-oriented: it favors as desirable particular trajectories of social change, and deliberately seeks to contribute to bringing them about. This is true of much resilience research, particularly that coming from longer standing traditions in action research (e.g., Hagmann et al. 2002, Lovell et al. 2002, Frost et al. 2006, Van Noordwijk and Leimona 2010, Campos et al. 2016).

Ross and Berkes (2014) have observed that certain forms of participatory research may directly contribute to building community resilience at the same time as they study communityscale responses to change and crisis. Examples of how this comes about include providing opportunities for reflection and deliberation, supporting development of new processes for social learning, and creating strong linkages across as well as within organizational levels. A recent example relevant to the case studies described in this paper is a collaboration between researchers at Arkansas Tech University and Dancing Rabbit Ecovillage, a sustainability-oriented intentional community in Missouri, USA (Lockyer 2017). Research aims and methodologies were developed in discussion with community members about their needs and interests. Research had various outcomes with benefits for both resilience of the host community itself and its capacity to promote wider societal change. Methods included provision to the community of facilities for recycling solid waste, which both facilitated sustainable personal practices and created opportunities to measure and monitor material throughputs. Results provided insights into the community's performance in its stated aims of providing high levels of personal and collective well-being while minimizing usage of fossil fuels and other nonrenewable resources. Findings have informed decision making within the community and fed into wider advocacy and outreach undertaken by community members. The main researcher, a graduate student, ultimately became a resident of the community and research director in its associated nonprofit organization, and in this capacity has been supporting further research. Although not explicitly focused on resilience, the study provides an example of how Mode 2 research can, at different levels, help enhance qualities identified by Berkes and Ross (2013) as associated with community resilience, including infrastructure, knowledge and learning, innovation and collaboration. It also shows how Mode 2 research can contribute to efforts toward transformation at higher levels in the panarchy.

In the rest of this paper I examine contributions of Mode 2 research to strengthening community resilience in the field of permaculture, an established methodology in practical efforts at building community resilience, in a largely vernacular sense, i.e., based primarily on informal rather than scientific understandings. The key aim is to explore interactions between largely informal processes of iterative learning embedded in permaculture approaches (described in more detail in Henfrey 2017) and more formal learning processes associated with academic research. I thus address the key research question: How can permaculture inform and enhance methodologies in applied resilience research? I address less directly the associated question of how formal research can inform and enhance permaculture as a social change methodology. In the next section I provide an overview of permaculture and its emerging relationship with research, and present case studies at three different scalar levels where permaculture has formed the basis of research design. In the discussion section I then assess general lessons from these case studies and previous literature on participatory resilience research. In conclusion, I tentatively suggest that such examples might indicate an emerging "Mode 3" research orientation. Mode 3 research incorporates into its methodologies analytical concepts and mechanisms for critical self-reflection derived from nonacademic research partners. In doing, it directly supports the efforts of these partners to build community resilience, in ways potentially transgressive of established research regimes.

\section{BACKGROUND: RESEARCH AS SOCIAL PERMACULTURE}

Permaculture is a design methodology for sustainable human habitats that takes inspiration from ways in which natural systems self-organize for resilience and productivity (Mollison and Holmgren 1978, Mollison 1979, Mollison and Slay 1988, Morrow 2006, Aranya 2012). In its contemporary usage, the term "permaculture" encompasses four distinct yet interrelated meanings, each relevant here to some degree: as a design methodology, as a bundle of methods and techniques, as a social movement, and as social philosophy (Ferguson and Lovell 2014). As a social philosophy, it is rooted in three core ethics, most simply stated as "Earth Care," "People Care," and "Fair Shares," and asserts that appropriate goals for social change lie at the intersection of these ethics. As a design methodology, it seeks to 
apply lessons derived from careful ongoing observation of natural systems in the deliberate design of human organizations (material and/or abstract) that simultaneously fulfill the three ethics in sustainable ways. Permaculture cofounder David Holmgren has derived from his work 12 basic permaculture design principles (Holmgren 2002). These principles can be viewed as generalizable heuristics supporting design for resilience: mobile equivalents to the rule of thumb approaches to navigating social-ecological complexity evident in many traditional resource management systems (Berkes 2008, Berkes et al. 2000). As a social movement, permaculture comprises a global community of dedicated social change practitioners, united by commitment to its social philosophy along with knowledge and application of its design approach and associated bundles of tools and techniques.

Permaculture design principles and processes lend themselves to, but do not directly specify, particular methods and techniques for achieving intended outcomes. Their areas of application are wideranging and include a range of social as well as practical fields (Henfrey and Penha-Lopes 2015). Agroecological and other physical methods are the applications most familiar to those outside the movement, and probably to most permaculture practitioners (Ferguson and Lovell 2014). The emerging field of social permaculture draws upon diverse techniques for creating nurturing social environments, conducive to personal growth and fulfillment and supporting harmonious and mutually enhancing relationships among people, often based on ecological models (MacNamara 2012). From this field derives a key argument in this paper: that research needs to be attentive to its own social dynamics, and in doing so can employ, among other tools, those of social permaculture.

Permaculture is a naturally experimental endeavor, in ways that imply close potential relationships with formal research. Its interventions at all levels are exploratory: each specific instance of design is unique. Even when it involves familiar techniques, these are applied in context-specific ways and combinations. Accordingly, permaculture design builds in ongoing processes of self-evaluation and readjustment, often modeled on the action learning cycle of intervention, observation, reflection, and planning. Each application of permaculture can therefore be considered an exercise, however informal and small scale, in action research (Chapman et al. 2014). The affinity with formal research processes has been pointed out in Environmental Anthropology, a field with strong traditions of applied and engaged research, with Holmgren's permaculture principles providing a conceptual link (Veteto and Lockyer 2008, Lockyer and Veteto 2013). However, a combination of widespread distrust toward the academy among permaculture practitioners, and permaculture's limited visibility, understanding, and/or credibility among academics have largely isolated it from formal research for most of its history (R. Scott 2010, unpublished manuscript, http:// robscott.net/2010/).

Efforts led by the British Permaculture Association, roughly over the past decade, have sought to strengthen and develop this link, both by encouraging better documentation and reporting by permaculture practitioners and by engaging professional researchers more closely with permaculture practice (see http:// www.permaculture.org.uk/research). The Association has created a research handbook for permaculture practitioners, initiated participatory field trials in key areas such as vegetable polycultures, forest gardening, and soil improvement, and set up a new Permaculture International Research Network involving several hundred researchers, practitioners, practitionerresearchers, and researcher-practitioners in over 60 countries worldwide. These developments have been presented as emergence of a new feature of the permaculture movement: the capacity to undertake its own documentation, reporting, and critical selfanalysis (Sears et al. 2013).

Permaculture principles advocate relationships of mutually enhancing two-way interchange between interacting systems, and between elements within systems. Ideally, then, in interactions with research the philosophy and practice of permaculture would exert significant influences upon the aims, conduct, methodologies, and outcomes of research. I examine such interactions in three case studies of participatory research that each to some degree incorporate permaculture in their design. I have taken a central role in each; these data are therefore presented, in part, as a reflective exercise and form of autoethnography. The case studies operate at successively broader geographical and conceptual scales: a local food initiative within County Durham in northeast England; a researcher-practitioner network affiliated with the Transition movement, of international scope but in practice with membership and activities predominantly in the UK; and a European-wide network of community-based sustainability initiatives and supporting organizations. They together provide an example of the "revolt" effect in resilience theory (Holling et al. 2002:75-76), where innovations originating in the local scale project became embedded in the design and operation of first a national and later an international research network.

The case studies illustrate three main ways in which permaculture has a natural affinity with applied resilience research, particularly conducive to Mode 2 collaboration. First, permaculture's core process of iterative and incremental cycles of action learning are a natural fit with the cyclic processes of collaborative learning at the heart of participatory action research (McIntyre 2008, Sears et al. 2013). Second, the same processes are conducive to the learning, innovation, collaboration, and cross-scale influence identified by Berkes and Ross (2013) as key dimensions of community resilience. Third, integrating the ethics, principles, and methods of permaculture into the heart of the research process bring to it the transformative potential that I identified in the introduction as a key operational ingredient of values-driven initiatives for community resilience.

\section{CASE STUDY 1: DURHAM LOCAL FOOD RESEARCH}

The first case study was a collaboration between the Anthropology Department at Durham University, my professional base at the time (2010-2011), and the Durham Local Food Network (Mycock 2011). The project was hosted by Transition Durham (of which I was at the time a core member), a local organization affiliated with the Transition movement. Transition is a global network of local initiatives that aim to build resilience in communities of place. Transition was initially motivated by threats from peak oil, climate change, and financial instability (Hopkins 2008). It is nowadays more commonly framed in terms of aspirations to create thriving local economies and cultures conducive to well-being and happiness (Hopkins 2015). 
Transition originated on a permaculture course at Kinsale Further Education College in Ireland, whose students chose as their final project to design a community-led local response to peak oil (Hopkins 2005). Its present form draws extensively both on vernacular discourses on resilience (Haxeltine and Seyfang 2009) and technical accounts of resilience science (Hopkins 2010). The direct linkage of theory and practice is deepening conceptual understandings of resilience in important ways (Henfrey and Giangrande 2017, Henfrey et al. 2017). Although some in the Transition movement consciously differentiate it from permaculture, Transition retains permaculture design among its core methodologies and many people are involved in both. Transition Durham, founded by a local permaculture teacher and many of whose core members have permaculture training, is closely linked with the local and regional permaculture networks (see http://northeastpermaculture.org.uk/networks). The Durham Local Food Network predates Transition Durham. By linking independent producers, processors, retailers, and consumers in the area, the Local Food Network aims to nurture resilience in a food system otherwise dominated by agribusiness and supermarket chains.

Collaborative from the outset, the research project was based around a Master's study, cosupervised by my permaculture teacher (who also founded and coordinated the Local Food Network) and me, and funded within an initiative to support collaborations between regional universities and local businesses in northeast England. Methodological design made extensive use of permaculture concepts, notably stacking, the assignment of multiple functions to a single element or process. By identifying research questions that also encompassed informational needs of the Local Food Network, the research student was able to gather data of both academic and practical value. Research made use of embedded methodologies based on participant observation as a local food activist. This approach allowed promotional work for the Network to double as ethnographic research, at the same time increasing the researcher's credibility and trust among members of the network. Previously disaggregated and fragmented data gathered on an ad hoc basis in the first few years of the Network's life represented an invaluable data archive. A concentrated period of in-depth research made use of and extended this resource to a far greater extent than previously possible. In short, an engaged methodology that made research directly responsive to practical needs and allowed the researcher to define her own role as a core organizer of the Network brought academic and practical aims into alignment and allowed synergies between them to arise.

In hindsight, it became clear that the project had, in effect, been an exercise in social permaculture. This did not result from any explicit intent, but was a natural consequence of designing and delivering it within the existing social processes of Transition Durham, which drew upon permaculture so routinely they had become an invisible part of group culture. A retrospective examination of the project showed the working methods in some way or another to have expressed all 12 Holmgren principles (Henfrey 2015, unpublished manuscript), which can be understood as design principles for resilient communities and socialecological systems.

Several features of the collaboration supported contributions to the Network's efforts at resilience-building. The research question, "What is the breadth and diversity of interest in and action upon local food in County Durham?" doubled as a scoping exercise for the Network through which it could locate its full range of supporters. Only a minority among these supporters were motivated by the same interests as its founders and coordinators. Addressing this question thus increased interconnection among diverse actors in the sector. By providing a space for communication, representation, and common action the research process promoted modularity, in that the local food sector, through the Network, now has some measure of presence as a coherent entity. This provides a mechanism for interactions across organizational scales, e.g., with local and higher levels of government, and within regional and national projects and networks concerned with local food, beyond the capacity of any individual member. For example, the Network was able to secure local authority funding for a web site and other promotional materials, and to partner with the County Durham Community Foundation on an ambitious county-wide project linking with similar local and regional initiatives nationwide. In this respect, the Network acts as a cultural keystone: a sociocultural complex that provides a generic linkage point via which actors, processes, and activities operating locally can engage with relevant processes at larger scales without being overwhelmed by them (Platten and Henfrey 2009). This enables the types of cross-scale interactions within the panarchy that support resilience in any nested multilevel system (Holling et al. 2002) and identified as crucial for community resilience (Berkes and Ross 2013). These are all features consistent with accounts of the emergence of resilience in regional economies via the growth of cooperative enterprise (Lewis and Conaty 2013). In my view, the same benefits could not have arisen in a Mode 1 research project. The Network would not have had the capacity to accommodate a researcher working in a conventional, disengaged sense, nor to act on findings or recommendations delivered in a detached way. Only by directly embedding research within the growth and operations of the Network was it possible to align academic and practical aims and outcomes.

\section{CASE STUDY 2: THE TRANSITION RESEARCH NETWORK}

The Transition Research Network (TRN) emerged from a combination of ad hoc research collaborations, of various kinds, between researchers and initiatives or projects in the Transition movement, and thematic meetings and workshops on the relationships between transition and research. Discussions at these events, and targeted research on the topic, showed the experiences of transition initiatives that had taken part in academic research had been mixed, and often negative (Kelly and Kelly 2013). Many had experienced Mode 1 research in particular as effectively modeling unsustainable patterns of natural resource exploitation characteristic of the fossil fuel era. Groups often felt they had been harvested for data and had given their time, energy, and knowledge for benefits that were either nonexistent or notional/aspirational and often not followed through. This was a pattern that became colloquially known as "extractive research" (cf. Chambers 2007). On the other hand, there were also examples of collaborations that were positive for all involved. Some published studies have been of great value to the movement as a whole, in terms of documentation and/or self-analysis (e.g., Haxeltine and Seyfang 2009, Seyfang 2009, North 2010). The 
main aim of TRN became to synthesize, learn from, and deepen this experience: identify factors that promote mutually beneficial research collaborations and support researchers and Transition groups to emulate these factors when they work together (Henfrey and Brangwyn 2013). Central to this aim was the permaculture concept of edge: ensuring that interchanges between elements or systems are mutually beneficial and synergistic, balanced and cooperative rather than exploitative.

Social permaculture became an explicit part of Transition Research Network working methods at a day-long workshop in Plymouth, southwest England, on 29 February 2012. Around 40 participants took part in a "research permablitz" (a permablitz is an exercise in which a group of people, coordinated by an experienced permaculture designer, work together intensively for a brief period, usually within a single day, to address a specific design challenge). This employed methods familiar in the Transition movement and social permaculture such as World Cafe and Open Space, which seek to maximize participation by ensuring everyone present has an opportunity to have a meaningful input into posing and/or addressing questions (Wates 2000). It also included discussions that used social-ecological systems such as ecovillages, forest gardens, and ocean harbors as metaphorical frameworks around which to explore key issues and identify design strategies for the network (TRN 2012). Findings from this event, further workshops, systematic study of experiences of Transition groups involved in research, and relevant literatures such as Participatory Action Research (Kindon et al. 2007) and social permaculture, fed into development of a transition research pattern language (TRN [date unknown]). The pattern language comprises a set of flexible guidelines for designing research collaborations as emergent social systems and/or knowledge cocreation communities, with properties that transcend those of both the Transition group or project and the research organization, and from which both gain tangible benefits.

TRN's contributions to resilience building are both remedial and constructive. In remedial terms, it sought to mitigate and ideally reverse the perceived negative effects of much Mode 1 research upon both the resilience of involved Transition groups and the personal resilience of group members taking part. Writing from personal experience, I have described the research culture that emerged as akin to a forest garden, a multilevel agroforestry complex widely seen as emblematic of temperate climate permaculture design (Henfrey 2014). I employ this metaphor to make the case for research collaborations designed to focus not just on generation of data that can fuel research careers, but also on strategic contributions at network level, practical contributions at the level of the local group, on the quality of the social environment, and on positive personal experiences. All of these "lower level" yields are likely to make positive contributions to personal, community, and social resilience. Use of participatory methods that employ the social technologies adopted and refined in Transition, social permaculture, and related fields ensures that research processes can build these in as immediate, ongoing, and core outcomes.

TRN also seeks to promote research that builds resilience at movement and even societal level, explicitly associating itself with other movements for "civic transitions" (Maxey et al. 2015). As a reflexive, iterative social movement that aspires to operate as a learning network, Transition, like permaculture, has obvious potential affinity with formal research. Adger (2000), among others, has noted that the human capacity for foresight is a key locus of difference between social (and hence community) resilience versus resilience in ecological systems lacking active human involvement. Improved capacities for research, i.e., cumulative processes for generating, critically examining and improving knowledge and understanding of key systemic processes, can improve the scope, relevance, and accuracy of such foresight. This is likely, in turn, to improve capacities for deliberate self-organization for resilience, as long as the attainment and application of this foresight do not undermine resilience in other ways. Accordingly, a key research priority identified by Transition Network was the capacity for self-evaluation, at both local initiative and movement level, of the effectiveness of practical interventions. This was addressed in the Monitoring and Evaluation for Sustainable Communities project, a Mode 2 collaboration involving Oxford University's Environmental Change Institute, Transition Network, and the Low Carbon Communities Network (Hobson et al. 2016). The success of the project in significant measure derived from thorough collaboration in research design and all subsequent stages of implementation. Another important factor was experience of boundary-crossing between research and community activism in the research team, most of whom were familiar with and comfortable in both roles.

Supporting Transition groups to collaborate more effectively with researchers, and researchers to contribute more effectively to Transition, can help foster long-term social and community resilience. It is possible that the experimental niches thus created for innovation around research methodologies could scale up via the revolt mechanism, particularly if at some point established research regimes cease to be viable. This would help increase resilience in wider mechanisms for knowledge creation, learning, evaluation, and planning, with benefits for social and/or socialecological resilience more generally.

\section{CASE STUDY 3: TREE AND ECOLISE}

European Community-Led Initiatives for a Sustainable Europe (ECOLISE) is an EU-wide meta-network of community-based sustainability and climate change initiatives that provides a common platform for networking, learning, collaboration, communication, and policy influence. Most of its members are national and international permaculture, Transition, and ecovillage organizations. ECOLISE member organizations thus represent large numbers of local groups and projects working in specific communities of place. The ECOLISE membership also includes a smaller number of what are termed Specialized Members, including research organizations and others whose main expertise is in areas such as education and communication. Specialized members do not directly represent any community group or network, but support the overall aims of ECOLISE and are prepared to contribute to meeting them by providing relevant specialist skills.

Significant impetus for the establishment of ECOLISE grew out of TREE, a research initiative that developed a proposal for European Union research funding. The TREE consortium included among its partners Transition Network, Global 
Table 1. Applications of permaculture principles in research design and consequences for community resilience.

\begin{tabular}{|c|c|c|c|c|}
\hline $\begin{array}{l}\text { Case } \\
\text { Study }\end{array}$ & Principle/s & How Applied & Effects on Research Processes & $\begin{array}{l}\text { Consequences for Community } \\
\text { Resilience }\end{array}$ \\
\hline $\begin{array}{l}\text { Durham Local } \\
\text { Food Research }\end{array}$ & $\begin{array}{l}\text { Stacking } \\
\text { (multifunctionality) }\end{array}$ & $\begin{array}{l}\text { Choosing methods that } \\
\text { simultaneously further both } \\
\text { academic and practical aims }\end{array}$ & $\begin{array}{l}\text { Reconciling and synergizing } \\
\text { academic } \\
\text { and applied outcomes }\end{array}$ & $\begin{array}{l}\text { Increased diversity and quality of local } \\
\text { networks; stronger links between local } \\
\text { and higher scales }\end{array}$ \\
\hline $\begin{array}{l}\text { Transition } \\
\text { Research } \\
\text { Network }\end{array}$ & $\begin{array}{l}\text { Edge (creating mutually } \\
\text { beneficial relationships }\end{array}$ & $\begin{array}{l}\text { Collaborative conception, } \\
\text { design, and execution of research }\end{array}$ & $\begin{array}{l}\text { Mobilizing practitioner } \\
\text { knowledge toward academic } \\
\text { aims and intellectual knowledge } \\
\text { toward practical aims }\end{array}$ & $\begin{array}{l}\text { Greater number and quality of } \\
\text { learning interactions }\end{array}$ \\
\hline $\begin{array}{l}\text { TREE and } \\
\text { ECOLISE }\end{array}$ & $\begin{array}{l}\text { Produce no waste } \\
\text { Creatively use } \\
\text { and respond to change }\end{array}$ & $\begin{array}{l}\text { Designing in alternative } \\
\text { implementation pathways not } \\
\text { dependent on project funding }\end{array}$ & $\begin{array}{l}\text { Continuation and mobilization } \\
\text { of knowledge and relationships } \\
\text { established during funding } \\
\text { application }\end{array}$ & $\begin{array}{l}\text { New collaboration platform at wider } \\
\text { geographical scale with learning } \\
\text { interactions centrally embedded in } \\
\text { goals and processes }\end{array}$ \\
\hline
\end{tabular}

Ecovillage Network (GEN), Gaia Education (the educational branch of GEN), along with research organizations including the Climate Change Impacts and Management research group at Lisbon University (CCIAM) and the Schumacher Institute (one of the coordinating organizations for Transition Research Network). The consortium's working methods drew upon the skills of all collaborators, including their social as well as intellectual and practical expertise. Central to the process was treating the funding application not as an end in itself, but as part of a wider exercise in shared learning to support establishment of an international, transdisciplinary community of practice. In other words, the common permaculture strategy of designing multiple immediate yields into the process itself ensured it would be worthwhile and bear fruit even if the initial funding application was unsuccessful (as turned out to be the case).

The deeper value of the exercise became apparent in early 2013, when core members of the TREE consortium came into contact with AEIDL, the European Association for Information on Local Development. AEIDL had, since 2009, been exploring the possibility of establishing a Europe-wide network of communitybased initiatives on sustainability and climate change. The TREE consortium engaged with these efforts, to which it brought its established relationships and working methods and excellent connections with relevant networks. This helped generate momentum that led to the legal founding of ECOLISE in 2014 and fed into its subsequent development as an organization. The TREE consortium's rapid and constructive response to the appearance of this new opportunity was possible because of the flexibility designed into its working processes. This in turn depended upon the strong linkages that had become established among member organizations, underpinned by high quality interpersonal relationships, which allowed emergence of productive synergies among organizational strengths and operational styles. In particular, it created strong shared understanding and common languages, processes, and goals for both research and practice-focused organizations.

An important consequence of the historical links between TREE and ECOLISE is that ECOLISE from the outset involved research organizations as active members and cocreators. Learning processes are built in to all aspects of the organization's operations, and draw upon a wide range of skills. These skills range from the informal and nonformal learning that is at the heart of permaculture design, ecovillage life, and the work of Transition initiatives, through the professional educational and communication skills that have emerged in these networks, to the advanced formal research and analytical capacities of universities and other specialist research organizations. With diverse and highly refined learning capabilities built in, ECOLISE has powerful capacities for social and organizational learning of types conducive to adaptive capacity and resilient operations. Conversely, these capacities are also available to member organizations, potentially increasing both their own resilience and their ability to contribute to wider efforts at building community, social, and social-ecological resilience.

\section{DISCUSSION: TOWARD A RESILIENT RESEARCH CULTURE}

The central postulate of this paper has been that some forms of transdisciplinary research can directly contribute to building community resilience. It has examined this claim specifically in relation to permaculture design, with reference to case studies at local, national, and international scales. Table 1 indicates one or more key permaculture principles (derived from Holmgren 2002 and/or Mollison and Slay 1988) identified as relevant to each case study, its methodological application, and the consequences both for the research itself and in terms of community resilience. Space constraints mean this is not comprehensive: thorough analysis of the Durham Local Food project revealed signs of all 12 Holmgren principles (Henfrey 2015, unpublished manuscript).

Each case study demonstrates specific ways in which application of permaculture design has changed research approaches and as a result enhanced the direct and indirect contributions of research to community resilience. In the Durham Local Food project, an engaged methodology based on the permaculture principle of stacking aligned academic and practical aims in ways that directly strengthened the Local Food Network, both an important feature of community resilience in its own right and contributor to wider efforts at resilience building. The Transition Research Network developed principles to enable research to contribute directly to building personal, social, and community resilience by close attention to personal and interpersonal experience, and to support increases in capacities for foresight, self-evaluation, and reflective action, and hence resilience, at community level. ECOLISE emerged partly from ongoing processes of relationship building and collaborative learning supported by simultaneous 
attention to multiple possible yields and outcomes, and connects its members through networks of collaboration and mutual learning at multiple scales. Cutting across all these initiatives and the scales they represent is the common theme of fostering mutually beneficial relationships of collaboration and collective learning. This theme is consistent with current understandings of social conditions conducive to community resilience (Berkes and Ross 2013), and research methodologies that can foster these (Ross and Berkes 2014, also cf. Ingram and Njikeu 2011).

The case studies exhibit a form of methodological pluralism that builds applied outcomes directly into the research process in order that it contributes to efforts to generate community resilience at the same time as it documents them. This is not an entirely new phenomenon in resilience research, whose methodologies and insights have drawn upon a rich variety of approaches in applied, participatory, and/or action-oriented research. The postmodern turn in Environmental Anthropology (e.g., Anderson 1996, Descola and Pálsson 1996, Ellen and Fukui 1996) influenced new approaches to ecology that consider the ecological perspectives and associated practices of indigenous and traditional resource users to have inherent scientific as well as practical merit (Berkes et al. 2000, Berkes 2008, Anderson 2010). The resulting wider view of ecology, critical of scientific hegemony (Escobar 1999), underpins in important ways the scientific concepts of socialecological resilience (Gunderson and Holling 2002) and community resilience (Berkes and Ross 2013). It was also a key epistemological driver of the emergence of the applied and transdisciplinary field of biocultural diversity (Maffi 2001). A recent example from applied resilience research showed that existing social and cultural practices of Guna indigenous peoples in Panama contribute directly to capacities for adaptation and transformation (Apgar et al. 2015).

Permaculture, described by one researcher as a "feral ecology" (Morris 2012), is another form of hybrid knowledge, which I have elsewhere described as a networked set of experiments in the deliberate generation of biocultural diversity with strong affinity with indigenous movements (Henfrey and Penha-Lopes 2015, Henfrey and Kenrick 2017). The call within permaculture and related social movements such as Transition and ecovillages for place-based, locally self-organized responses to global environmental, social, and economic issues also implies epistemological diversity. All of this illustrates the concept of "critical complexity": the need for epistemological plurality in the study of complex systems, including recognizing the normative dimensions of any system framing and revealing the assumptions and values behind dominant framings (Audouin et al. 2013, cf. Leach et al. 2010). Important features of critical complexity revealed in previous resilience research include the inclusion within transdisciplinary collaborations of diverse perspectives (Audouin et al. 2013, Stone-Jovicich 2015), taking account of different patterns of interaction among these perspectives (Beers et al. 2016), and transgression of scalar, institutional, and epistemological boundaries (Stokols et al. 2013). A logical conclusion is that resilience theory might seek to emulate the conceptual and processual pluralism of fields such as social ecology and critical political ecology (Stokols et al. 2013, Stone-Jovicich 2015). This further implies that research that aims to contribute directly to the generation of community resilience, i.e., in its conduct as well as prospective applications or other impacts, will involve open learning, including critical reflection upon and the possibility of transformation in its own epistemological premises. In the absence of such critical reflection, much resilience science risks becoming complicit, often unwittingly, in conservative political, economic, and development agendas that reinforce dominant regimes and hence fail to address, indeed often exacerbate, underlying causes of ecological and social degradation (MacKinnon and Derickson 2013, Bassett and Fogelman 2013).

Taken to its logical conclusion, this need for epistemological diversity implies ongoing cocreation of a unique working culture associated with each single, placed-based research collaboration. Because the nature of this will be influenced as much by the subjects as the researchers, and by its own specificities of context, the result will be ever-widening diversity of knowledge-generating processes (cf. Rogers et al. 2013, Tschakert and Dietrich 2010). Wider societal learning capacities, and hence adaptive capacities, and hence resilience, would be emergent upon these local processes, in much the same way as landscape-level resilience depends on heterogeneity in ecological processes at more local scales (Berkes and Folke 2002) and social-ecological resilience at global levels depends upon biocultural diversity (Maffi 2001, Berkes et al. 2002). The deliberate cultivation of diverse localized cultures of knowledge cocreation is an instance of the tendency of action research, in its earliest formulations, to disrupt established, potentially conservative patterns of behavior and/or information exchange (Hobman and Walker 2015). In terms of present-day resilience science, we can see this as an instance of the revolt effect. In my view it stretches the definition of Mode 2 science, which does not necessarily involve any form of transformative impulse arising from systematic critical reflection and consequent transgression of dominant knowledge generation regimes.

I tentatively propose making these observations the basis of a working definition of Mode 3 science: pluralistic in orientation, reflexive about its own epistemological choices, and explicit about the political positions and other assumptions that underlie these, and consciously and deliberately working toward overtly stated social and/or environmental goals. These goals will be at least potentially - and, if they relate to resilience building in terms compatible with the perspectives and analyses that inform many community-led initiatives, in all likelihood necessarilytransformative of existing social and political conditions. I have described how permaculture, when simultaneously both the subject of research and a framework for research design, can be the basis of such a Mode 3 resilience science. This is one of many possible forms of Mode 3 resilience science, each of them characterized by radical transdisciplinary orientations and consequent epistemological hybridity.

\section{CONCLUSION: BEYOND MODE 2 RESILIENCE SCIENCE?}

Returning to the Sterling (2001) typology of sustainability education referred to in the introduction, I noted in the introduction the correspondence of Mode 2 research, i.e., research that supports efforts at building community resilience, with Sterling's second level, of education for sustainability. Mode 3 community resilience research of the type postulated here would correspond to Sterling's third level, of sustainability education as sustainability practice, in that it seeks as far as possible to model 
in its own conduct the resilient communities, and in particular learning and knowledge production activities within these, whose creation it seeks to support.

Table 2 summarizes the properties of research in these three modes. Mode 1 research is ostensibly neutral in terms of its social and political orientation. It is conducted either for its own sake or in order to provide purely technical data to support resolution of social problems it has no role in defining. Mode 2, in contrast, explicitly recognizes its position in relation to stated social values. Mode 3 research goes further in asserting that acting in accordance with its stated values implies transformation of prevalent societal norms and perspectives relating to dominant political and economic institutions. While Mode 2 permits and draws upon interchange among different forms of knowledge and ways of knowing, Mode 3 seeks integrative forms of understanding that transcend the limitations of any single one of these. Accordingly, while Mode 2 is reflexive, in that both the knowledge produced and the methods employed in doing so are assessed against their ability to respond to its stated goals, Mode 3 is critical of the very conditions of its own production, recognizing that it has been shaped by the same institutions, perspectives, and processes whose transformation it seeks to help bring about.

Table 2. Comparison of research in Modes 1, 2, and 3.

\begin{tabular}{llll}
\hline \hline & Social Orientation & Epistemology & Self-Orientation \\
\hline Mode 1 & Neutral & Uniform & Unreflexive \\
Mode 2 & Positional & Pluralistic & Reflexive \\
Mode 3 & Transformative & Integrative & Critical \\
\hline
\end{tabular}

Resilience science has strong traditions of participatory action research that embody many of the features that I suggest characterize Mode 3. It remains possible that rather than a new mode of resilience research, the analysis here highlights existing features of Mode 2 research that might be made more explicit and developed further. Exploring this could involve deliberately setting up research collaborations that fit the proposed definition of Mode 3. In such collaborations, resilience would be defined and operationalized in ways consistent with those used by participating community-based actors. The social methodologies of community partners would be deployed as central features of research design. Such research would then be subjected to rigorous evaluation, particularly in terms of its effects on community resilience. This evaluation would be most effective if employing both Mode 1 approaches - seeking to define and measure resilience in terms not influenced by the social goals of resilience practitioners - and Mode 2 approaches in which resilience scientists and community-based actors collaboratively define resilience and identify suitable approaches for its measurement. At the very least this would encourage deeper reflection on the nature and conduct of resilience research, and provide insights as to how to conduct it more effectively.

Responses to this article can be read online at: http://www.ecologyandsociety.org/issues/responses. php/9916

\section{Acknowledgments:}

Thanks to Rafter Sass Ferguson for extensive and insightful comments on an early version of this manuscript, two anonymous reviewers both of whom provided very useful recommendations, Gil Penha-Lopes for ongoing support, Eamon O'Hara for feedback on the ECOLISE case study, and colleagues in Transition Durham, the Transition Research Network, and ECOLISE who took part in the activities reported as case studies.

\section{LITERATURE CITED}

Adger, W. N. 2000. Social and ecological resilience: are they related? Progress in Human Geography 24(3):347-364. http://dx. doi.org/10.1191/030913200701540465

Anderson, E. N. 1996. Ecologies of the heart. Emotion, belief and the environment. Oxford University Press, Oxford, UK.

Anderson, E. N. 2010. The pursuit of ecotopia. Lessons from indigenous and traditional societies for the human ecology of our modern world. Praeger, Santa Barbara, California, USA.

Apgar, M. J., W. Allen, K. Moore, and J. Ataria. 2015. Understanding adaptation and transformation through indigenous practice: the case of the Guna of Panama. Ecology and Society 20(1):45. http://dx.doi.org/10.5751/ES-07314-200145

Aranya, 2012. Permaculture design. A step-by-step guide. Permanent Publications, East Meon, UK.

Audouin, M., R. Preiser, S. Nienaber, L. Downsborough, J. Lanz, and S. Mavengahama. 2013. Exploring the implications of critical complexity for the study of social-ecological systems. Ecology and Society 18(3):12. http://dx.doi.org/10.5751/ES-05434-180312

Barry, J. 2012. The politics of actually existing unsustainability. Oxford University Press, Oxford, UK. http://dx.doi.org/10.1093/ acprof:oso/9780199695393.001.0001

Bassett, T. J., and C. Fogelman. 2013. Déjà vu or something new? The adaptation concept in the climate change literature. Geoforum 48:42-53. http://dx.doi.org/10.1016/j.geoforum.2013.04.010

Beers, P., B. van Mierlo, and A.-C. Hoes. 2016. Toward an integrative perspective on social learning in system innovation initiatives. Ecology and Society 21(1):33. http://dx.doi. org/10.5751/ES-08148-210133

Berkes, F., 2008. Sacred ecology: traditional ecological knowledge and resource management. Second edition, revised. Routledge, London, UK.

Berkes, F., J. Colding, and C. Folke. 2000. Rediscovery of traditional ecological knowledge as adaptive management. Ecological Application 10(5):1251-1262. http://dx.doi. org/10.1890/1051-0761(2000)010[1251:ROTEKA]2.0.CO;2

Berkes, F., J. Colding, and C. Folke, editors. 2002. Navigating social and ecological systems: building resilience for complexity and change. Cambridge University Press, Cambridge, UK. http:// dx.doi.org/10.1017/CBO9780511541957

Berkes, F., and C. Folke. 2002. Back to the future: ecosystem dynamics and local knowledge. Pages 121-146 in L. H. Gunderson and C. S. Holling, editors. Panarchy: understanding 
transformations in human and natural systems. Island Press, Washington D.C., USA.

Berkes, F., and H. Ross. 2013. Community resilience: toward an integrated approach. Society and Natural Resources 26(1):5-20. http://dx.doi.org/10.1080/08941920.2012.736605

Campos, I. S., F. M. Alves, J. Dinis, M. Truninger, A. Vizinho, and G. Penha-Lopes. 2016. Climate adaptation, transitions, and socially innovative action-research approaches. Ecology and Society 21(1):13. http://dx.doi.org/10.5751/ES-08059-210113

Chambers, R., 2007. From PRA to PLA and pluralism: practice and theory. IDS Working Paper 286. Institute of Development Studies, Brighton, UK.

Chapman, P., R. Sinfield, and C. Warburton-Brown, editors. 2014. The permaculture research handbook. Permaculture Association, Leeds, UK. [online] URL: https://www. permaculture.org.uk/research/research-handbook-and-training

Descola, P., and G. Pálsson, editors. 1996. Nature and society. Routledge, London, UK. http://dx.doi.org/10.4324/9780203451069

Ellen, R. F., and K. Fukui, editors. 1996. Redefining nature. Berg, Oxford, UK.

Escobar, A. 1999. After nature: steps to an antiessentialist political ecology. Current Anthropology 40(1):1-30. http://dx.doi. org/10.1086/515799

Ferguson, R. S., and S. T. Lovell. 2014. Permaculture for agroecology: design, movement, practice, and worldview. A review. Agronomy for Sustainable Development 34(2):251-274. http://dx.doi.org/10.1007/s13593-013-0181-6

Frost, P., B. Campbell, G. Medina, and L. Usongo. 2006. Landscape-scale approaches for integrated natural resource management in tropical forest landscapes. Ecology and Society 11 (2):30. http://dx.doi.org/10.5751/ES-01932-110230

Gunderson, L. H., and C. S. Holling, editors 2002. Panarchy: understanding transformations in human and natural systems. Island Press, Washington, D.C., USA.

Hagmann, J. R., E. Chuma, K. Murwira, M. Connolly, and P. Ficarelli. 2002. Success factors in integrated natural resource management R\&D: lessons from practice. Conservation Ecology 5(2):29. [online] URL: http://www.consecol.org/vol5/iss2/art29/

Haxeltine, A., and G. Seyfang. 2009. Transitions for the people: theory and practice of 'transition' and 'Resilience' in the UK's transition movement. Working Paper 134, Tyndall Centre for Climate Change Research, University of East Anglia, Norwich, UK.

Henfrey, T. 2014. Edge, empowerment and sustainability: paraacademic practice as applied permaculture design. Pages 121-139 in A. Wardrop and D. M. Withers, editors. The para-academic handbook: a toolkit for making-learning-creating-acting. HammerOn Press, London, UK.

Henfrey, T. 2017. Permaculture education as ecology of mind: the head, hands and heart of transformation. Pages 171-184 in J. Winn and R. Hall, editors. Mass intellectuality and democratic leadership in higher education. Bloomsbury, London, UK.
Henfrey, T., and B. Brangwyn. 2013. The transition research primer v1.0. Transition Research Network, Totnes, UK. [online] URL: http://www.transitionresearchnetwork.org/transition-research-primer. html

Henfrey, T., and N. Giangrande. 2017. Transition and resilience. Pages 87-110 in T. Henfrey, G. Maschkowski, and G. PenhaLopes, editors. Resilience, community action and societal transformation. Permanent Publications, East Meon, UK.

Henfrey, T., and J. Kenrick. 2017. Climate, commons and hope: the transition movement in global perspective. Pages 161-190 in T. Henfrey, G. Maschkowski, and G. Penha-Lopes, editors. Resilience, community action and societal transformation. Permanent Publications, East Meon, UK.

Henfrey, T., G. Maschowski, and G. Penha-Lopes, editors. 2017. Resilience, community action and societal transformation. Permanent Publications, East Meon, UK.

Henfrey, T., and G. Penha-Lopes. 2015. Permaculture and climate change adaptation: inspiring social, ecological, economic and cultural responses. Permanent Publications, East Meon, UK.

Hobman, E. V., and I. Walker. 2015. Stasis and change: social psychological insights into social-ecological resilience. Ecology and Society 20(1):39. http://dx.doi.org/10.5751/ES-07260-200139

Hobson, K., J. Hamilton, and R. Mayne. 2016. Monitoring and evaluation in UK low-carbon community groups: benefits, barriers and the politics of the local. Local Environment 21 (1):124-136. http://dx.doi.org/10.1080/13549839.2014.928814

Holling, C. S., L. H. Gunderson, and G. D. Peterson. 2002. Sustainability and panarchies. Pages 63-102 in L. H. Gunderson and C. S. Holling, editors. Panarchy: understanding transformations in human and natural systems. Island Press, Washington, D.C., USA.

Holmgren, D. 2002. Permaculture: principles and pathways beyond sustainability. Holmgren Design Services, Melliodora, Australia.

Hopkins, R., editor. 2005. Kinsale 2021: an energy descent action plan. Kinsale Further Education College, Kinsale, Republic of Ireland. [online] URL: http://www.transitionus.org/sites/default/ files/KinsaleEnergyDescentActionPlan.pdf

Hopkins, R. 2008. The transition handbook. Green Books, Totnes, UK.

Hopkins, R. 2010. Localisation and resilience at the local level: the case of Transition Town Totnes. Dissertation, Plymouth University, Plymouth, UK.

Hopkins, R. 2015. 21 stories of transition. Transition Network, Totnes, UK.

Ingram, V., and J. Njikeu. 2011. Sweet, sticky, and sustainable social business. Ecology and Society 16(1):37. http://dx.doi. org/10.5751/ES-03930-160137

Kelly, U., and R. Kelly. 2013. Experiences of transition research. Transition Research Network. [online] URL: http://www. transitionresearchnetwork.org/experiences.html

Kindon, S., R. Pain, and M. Kesby. 2007. Participatory action research approaches and methods: connecting people, participation and place. Routledge, London, UK. 
Leach, M., I. Scoones, and A. Stirling. 2010. Dynamic sustainabilities: technology, environment, social justice. Earthscan, London, UK.

Lewis, M., and P. Conaty. 2013. The resilience imperative. New Society Publishers, Gabriola Island, British Columbia, Canada.

Lockyer, J. 2017. Community, commons, and degrowth at Dancing Rabbit Ecovillage. Journal of Political Ecology 24:519-542.

Lockyer, J., and J. Veteto, editors. 2013. Environmental anthropology engaging ecotopia: bioregionalism, permaculture and ecovillages. Berghahn Books, New York, New York, USA.

Lovell, C., A. Mandondo, and P. Moriarty. 2002. The question of scale in integrated natural resource management. Conservation Ecology 5(2):25. [online] URL: http://www.consecol.org/vol5/ iss $2 / \operatorname{art} 25 /$

MacKinnon, D., and K. D. Derickson. 2013. From resilience to resourcefulness: a critique of resilience policy and activism. Progress in Human Geography 37:253-270. http://dx.doi. org/10.1177/0309132512454775

MacNamara, L. 2012. People and permaculture. Permanent Publications, East Meon, UK.

Maffi, L., editor. 2001. On biocultural diversity: linking language, knowledge and the environment. Smithsonian Institution Press, Washington, D.C., USA.

Magis, K. 2010. Community resilience: an indicator of social sustainability. Society and Natural Resources 23(5):401-416. http://dx.doi.org/10.1080/08941920903305674

Maxey, L., T. Henfrey, S. Chamberlin, C. Bird, and J. Gonzales, 2015. Radical civic transitions: networking and building civic solutions. ACME 14(2):431-441.

McIntyre, A. 2008. Participatory action research. Qualitative Research Methods Series Volume 52. Sage, Thousand Oaks, California, USA.

Mollison. B. 1979. Permaculture Two. Practical design for town and country in permanent agriculture. Tagari, Tyalgum, Australia.

Mollison, B., and D. Holmgren. 1978. Permaculture one. A perrenial agriculture for human settlements. Tagari, Tyalgum, Australia.

Mollison, B., and R. M. Slay. 1988. Permaculture. A designer's manual. Tagari, Tyalgum, Australia.

Morris, F. A. 2012. When ecology goes feral. Wageningen Journal of Life Sciences 59:7-9. http://dx.doi.org/10.1016/j.njas.2012.01.003

Morrow, R. 2006. An Earth user's guide to permaculture. Second edition. Permanent Publications, East Meon, UK.

Mycock, A. 2011. 'Local Food' systems in County Durham: the capacities of community initiatives and local food businesses to build a more resilient local food system. Thesis. Durham University, Durham, UK.

North, P. 2010. Eco-localisation as a progressive response to peak oil and climate change-a sympathetic critique. Geoforum 41 (4):585-594. http://dx.doi.org/10.1016/j.geoforum.2009.04.013
Orr, D. 1994. Earth in mind. Island Press, Washington, D.C., USA.

Platten, S., and T. Henfrey. 2009. The Cultural Keystone Concept: Insights from Ecological Anthropology. Human Ecology 37 (4):491-500. http://dx.doi.org/10.1007/s10745-009-9237-2

Regeer, B., and J. Bunders. 2009. Knowledge co-creation: interaction between science and society. Preliminary studies and background studies, number V.10e. RMNO, Den Haag, The Netherlands.

Rogers, K. H., R. Luton, H. Biggs, R. Biggs, S. Blignaut, A. G. Choles, C. G. Palmer, and P. Tangwe. 2013. Fostering complexity thinking in action research for change in social-ecological systems. Ecology and Society 18(2):31. http://dx.doi.org/10.5751/ ES-05330-180231

Ross, H., and F. Berkes. 2014. Research approaches for understanding, enhancing, and monitoring community resilience. Society and Natural Resources 27(8):787-804. http://dx.doi. org/10.1080/08941920.2014.905668

Sears, E., C. Warburton-Brown, T. Remiarz, and R. S. Ferguson. 2013. A social learning organisation evolves a research capability in order to study itself. Poster presentation at the Tyndall Centre Radical Emissions Reduction Conference, London, UK, 10-11 December. [online] URL: http://bit.ly/2iVwbBP

Seyfang, G. 2009. Green shoots of sustainability: the 2009 transition movement survey. Transit Network, Totnes, UK. [online] URL: https://transitionculture.org/wp-content/uploads/greenshoots-of-sustainability.pdf

Sterling, S. 2001. Sustainable education: re-visioning learning and change. Schumacher Briefing No. 6. Green Books, Dartington, UK.

Stokols, D., R. Perez Lejano, and J. Hipp. 2013. Enhancing the resilience of human-environment systems: a social-ecological perspective. Ecology and Society 18(1):7. http://dx.doi. org/10.5751/ES-05301-180107

Stone-Jovicich, S. 2015. Probing the interfaces between the social sciences and social-ecological resilience: insights from integrative and hybrid perspectives in the social sciences. Ecology and Society 20(2):25. http://dx.doi.org/10.5751/ES-07347-200225

Transition Research Network (TRN). 2012. New knowledge for resilient futures. Workshop Report. Transition Research Network. [online] URL: http://www.transitionresearchnetwork.org/ uploads/1/2/7/3/12737251/trn plymouth report final version.pdf

Transition Research Network (TRN). [date unknown]. A pattern language for transition research. Transition Research Network. [online] URL: http://patterns.transitionresearchnetwork.org

Tschakert, P., and K. A. Dietrich. 2010. Anticipatory learning for climate change adaptation and resilience. Ecology and Society 15 (2):11. http://dx.doi.org/10.5751/ES-03335-150211

Van Noordwijk, M., and B. Leimona. 2010. Principles for fairness and efficiency in enhancing environmental services in Asia: payments, compensation, or co-investment? Ecology and Society 15(4):17. http://dx.doi.org/10.5751/ES-03664-150417 
Veteto, J. R., and J. Lockyer. 2008. Environmental anthropology engaging permaculture: moving theory and practice toward sustainability. Culture \& Agriculture 30(1-2):47-58. http://dx.doi. org/10.1111/j.1556-486X.2008.00007.X

Walker, B., C. S. Holling, S. R. Carpenter, and A. Kinzig. 2004. Resilience, adaptability and transformability in social-ecological systems. Ecology and Society 9(2):5. http://dx.doi.org/10.5751/ ES-00650-090205

Wates, N. 2000. The community planning handbook. Earthscan, London, UK. 